\title{
Dinâmica Espacial e Temporal da Inovação no Estado de São Paulo: Uma Análise das Externalidades de Diversificação e Especialização
}

\author{
Rosa Livia Montenegro - Eduardo Gonçalves - Eduardo Almeida
}

Submetido: 11 de abril de 2010; aceito para publicação: 16 de julho de 2011

Resumo: O trabalho avalia em que medida o grau de especialização ou diversidade pode afetar o desempenho inovador regional. Além disso, outros fatores determinantes da inovação são considerados, como a capacidade de realização de $\mathrm{P} \& \mathrm{D}$, o nível de escolaridade e a defasagem temporal da inovação. A base de dados é organizada em função das 63 microrregiões do Estado de São Paulo no período entre 1996 e 2003, e submetida a modelos de dados em painel espacial dinâmico. Os principais resultados revelam que a diversidade e a especialização produtiva são igualmente importantes para explicar o desempenho inovador das microrregiões.

Palavras-Chave: sistema regional de inovação, externalidades de diversificação e especialização, modelo dinâmico de dados em painel.

Os autores agradecem o apoio financeiro do Conselho Nacional de Desenvolvimento Científico e Tecnológico (CNPq) e da Fundação de Amparo à Pesquisa do Estado de Minas Gerais (FAPEMIG) e da Universidade Federal de Juiz de Fora para a elaboração deste artigo

Rosa Livia Montenegro

Mestre em Economia Aplicada pelo programa de Pós-Graduação em Economia (PPGE) da UFJF, Bolsista de Desenvolvimento Tecnológico Indiustrial do CNPq - Nível 2 - CEDEPLAR-UFMG Endereço para contato: Av. Antônio Carlos, n. 6627 - UFMG/FACE - CEP: 31270-901 - Belo Horizonte, Minas Gerais - E-mail: rosalivia@gmail.com

Eduardo Gonçalves

Professor Adjunto, Pesquisador do CNPq e Pesquisador da FAPEMIG - Programa de Pós-Graduação em Economia (PPGE) da Universidade Federal de Juiz de Fora (UFJF) - Endereço para contato: Faculdade de Economia, UFJF - Campus Universitário, Rua José Lourenço Kelmer, s/n, São Pedro CEP: 36036-900 - Juiz de Fora - Minas Gerais E-mail: eduardo.goncalves@ufjf.edu.br

Eduardo Almeida

Professor Adjunto, Pesquisador do CNPq e Pesquisador da FAPEMIG -Programa de Pós-Graduação em Economia (PPGE) da Universidade Federal de Juiz de Fora (UFJF) - Endereço para contato: Faculdade de Economia UFJF Campus Universitário - Rua José Lourenço Kelmer, s/n, São Pedro CEP: 36036-900 - Juiz de Fora - Minas Gerais - E-mail: eduardo.almeida@ufjf.edu.br 
Abstract: The aim of this article is to assess the extent to which the degree of specialization or diversity externalities may affect the regional innovative performance. Additionally, the influence of other regional factors on the innovative output is examined, such as regional R\&D capacity, schooling of local population and the temporal lag of innovation. The database is organized into 63 microregions of the state of São Paulo from 1996 to 2003. These data were analyzed by means of dynamic spatial panel data models. The main result shows that diversity and specialization externalities are equally important to the microregion's innovative performance.

Keywords: regional innovation system, diversity and specialization externalities, dynamic panel data models

JEL classification: $\mathrm{C} 23, \mathrm{O} 18, \mathrm{O} 31$

\section{Introdução}

A distribuição espacial da inovação e a composição da atividade econômica local são temas intimamente relacionados. De um lado, com base nos trabalhos de Marshall (1982), Arrow (1962) e Romer (1986), Glaeser et al. (1992) consideram as externalidades decorrentes da concentração geográfica em determinado setor como os principais fatores no processo de criação e difusão de conhecimento relevante para a geração de inovações.

Por outro lado, Jacobs (1969) considera a diversidade econômica como principal motor do processo de inovação. No primeiro caso, a proximidade geográfica favoreceria a transmissão intrassetorial de conhecimento e a especialização, por sua vez, encorajaria maior transmissão e troca de conhecimento, ideias e informação, seja tácita ou codificada, e facilitaria o processo de imitação de produtos e processos, além de incrementar as interações de negócios e circulação interfirmas de pessoal qualificado. No segundo caso, as principais fontes de externalidades seriam externas ao setor em que firma inovadora opera. Nesse sentido, uma base industrial mais diversificada promoveria maiores oportunidades para imitar, compartilhar e combinar ideias e práticas através dos setores, o que ocorreria com maior frequência em centros urbanos mais densamente ocupados. Com base nesses argumentos teóricos, intenso debate foi motivado por 
trabalhos empíricos que testaram a preponderância do tipo de externalidade em termos de fator explicativo do processo de aglomeração espacial da inovação. Entretanto, nem sempre foi possível estabelecer conclusões consensuais sobre o tema (Beaudry e Schiffauerova, 2009). Este artigo tem por objetivo explicar os determinantes da concentração regional da inovação no Estado de São Paulo, destacando o papel das externalidades de especialização e de diversificação industrial. Sobre esse aspecto, o trabalho incorpora sugestão da literatura que sustenta a necessidade de testar duas medidas empíricas das externalidades de diversificação e de especialização porque ambas podem não ser, necessariamente, mutuamente excludentes (Koo, 2005; Paci e Usai, 2000). A utilização de dois indicadores, ao invés de um só, para representar os dois tipos de externalidades é necessário porque enquanto o grau de especialização é um aspecto referente ao setor econômico de determinado sistema produtivo local, o grau de diversidade refere-se ao território como um todo. Logo, é possível haver inúmeras combinações possíveis entre níveis diferentes de especialização de um setor e graus de diversidade da área em que tais setores estão localizados.

Além desse aspecto, a motivação deste artigo está centrada na necessidade de haver maior aprofundamento e compreensão da relação entre a difusão de conhecimento tecnológico e a geração regional de inovações. Dessa forma, além da influência das externalidades de especialização e de diversificação sobre a capacidade regional de inovar, outros determinantes da inovação também serão considerados. A análise dos determinantes da inovação parte, em geral, da estrutura teórica conhecida como função de produção do conhecimento, desenvolvida inicialmente por Griliches (1979). Entre as várias modificações que permitem a inclusão de variáveis de controle nessa função, situa-se a de Cabrer-Borrás e Serrano-Domingo (2007).

A expansão do modelo permitiu levar em consideração a difusão inter-regional do conhecimento (externalidades de conhecimento), os esforços de $\mathrm{P} \& \mathrm{D}$ da economia local em período anterior, a dotação de capital humano das regiões e a composição da atividade econômica local, que podem dar origem a externalidades decorrentes da estrutura produtiva especializada e/ou diversificada. Ao contrário do trabalho citado acima, o presente artigo utiliza um método relativamente pouco usado no tema, a saber, o modelo de dados em painel espacial dinâmico, com tratamento da dependência espacial e 
da endogeneidade temporal. Essa metodologia será empregada sobre uma base de dados que cobre todos os anos do período compreendido entre 1996-2003 para microrregiões de São Paulo. Isso permite uma investigação espacial e temporal do progresso do sistema inovativo em São Paulo. Como o Estado de São Paulo é o principal centro econômico do País, não somente pela concentração de atividades industriais, e de instituições financeiras, mas também pela presença de sede de grandes grupos nacionais e internacionais com ampla infraestrutura científica e tecnológica, seu estudo permite identificar também as principais características do sistema de inovação brasileiro.

Além desta introdução, este trabalho se organiza em mais cinco seções. A segunda seção abrange a revisão de literatura empírica sobre as externalidades de diversificação e especialização; a terceira seção aborda o sistema de inovação do Estado de São Paulo; a quarta apresenta o modelo empírico usado, assim como outros aspectos metodológicos; a quinta discute os resultados das estimações dos modelos econométricos; por fim, na sexta seção são tecidas as conclusões do trabalho, salientando medidas de políticas públicas para o sistema de inovação de São Paulo.

\section{Revisão de Literatura}

A literatura sobre determinantes regionais da inovação tem destacado, em particular, a existência dos transbordamentos de conhecimento tecnológico e o papel da composição da atividade econômica regional na geração de externalidades. Assim, há argumentos teóricos e evidência empírica mista sobre o papel da especialização e da diversidade da estrutura produtiva regional. Em parte, o crescente interesse no tema se deve aos vínculos entre os transbordamentos de conhecimento e a teoria de crescimento endógeno (Romer, 1986; 1990), pela qual aqueles produzem retornos crescentes de escala no interior de regiões geograficamente delimitadas e, em consequência, altas taxas de crescimento (Glaeser et al., 1992).

A proximidade entre as firmas inovadoras facilita o processo de compartilhamento e difusão do conhecimento tecnológico. Isso ocorre não somente entre as firmas inovadoras que possuem seu próprio esforço em pesquisa, mas também a partir do compartilhamento do 
P\&D desenvolvido por outras instituições locais, que são geralmente as fontes de capacidade inovativa de muitas indústrias. O espaço geográfico é visto como meio pelo qual o conhecimento tecnológico pode transbordar e promover mais inovação pela tendência de fazer empresas se aglomerarem para tirarem proveito de conhecimento tácito e não codificado, provenientes de outras empresas inovadoras e de instituições públicas e privadas de pesquisa, que compõem a infraestrutura tecnológica regional. Contudo, o transbordamento possui limites geográficos definidos, tendo sua ocorrência diminuída à medida que aumenta a distância geográfica (Acs e Audretsch,1989; Jaffe et al.,1993; Audretsch e Feldman, 1996). A relação entre aglomeração e ocorrência de transbordamento de conhecimento é de dependência mútua (Koo, 2007). A aglomeração de empresas inovadoras é resultante da maior difusão do conhecimento no território e, ao mesmo tempo, promove tal difusão em decorrência dos transbordamentos de conhecimento.

Além dos transbordamentos, a composição da atividade econômica também explicaria a concentração regional da inovação. A ideia de que a concentração da inovação pode ser resultado não somente da concentração de pessoas e atividades produtivas, mas também da aglomeração de indústrias especializadas em um setor é bastante discutida na literatura. Do ponto de vista das firmas, a explicação para o fenômeno da concentração espacial é a existência de externalidades positivas ou economias de aglomeração, que podem ser entendidas como de urbanização (Jacobs, 1969) ou de localização (Marshall, 1982).

O trabalho clássico de Marshall (1982) descreve as vantagens da concentração de indústrias especializadas em certas localidades. Muitas são as causas que levariam à localização das indústrias, como as condições físicas geográficas e o fácil acesso às vias de escoamento da produção. Outro fator pode ser considerado de caráter acidental, como uma indústria beneficiada pelo desenvolvimento local e influenciada pelo fácil comércio.

Segundo o autor, uma indústria concentrada em certas localidades tem a vantagem de criar mercado de trabalho com mão de obra especializada. Além disso, com indivíduos que possuem a mesma profissão e conhecimentos técnicos especializados, este mercado constante para a mão de obra especializada se depara com alto poder de empre- 
gabilidade, pois os patrões sempre disporiam de uma boa seleção de indivíduos dotados de especialização na área. A partir do trabalho de Glaeser et al. (1992), as externalidades de especialização passaram a ser referidas pelo acrônimo MAR por causa das contribuições dos autores Marshall (1982), Arrow (1962) e Romer (1986).

Se, para Marshall (1982), o que gera externalidades é a especialização da cidade num mesmo setor industrial, para Jacobs (1969) a principal fonte e a mais significativa das externalidades é a diversidade de atividades econômicas desenvolvidas nas cidades. A interação entre as pessoas nas cidades na geração de novas ideias e produtos explica o processo de difusão da inovação e os transbordamentos proporcionados pelas indústrias de diversos setores (Jacobs, 1969). A significativa contribuição das interações consiste na explicação de que a concentração de economias de aglomeração em áreas urbanas permite atingir maior eficiência estática reduzindo, assim, a incerteza e o risco do processo inovador (Wood, 2001).

Jacobs (1969) considera que os transbordamentos interindustriais são as mais importantes fontes da criação do novo conhecimento. As externalidades de diversificação que ocorrem entre os setores industriais são favorecidas pela transferência de conhecimento que vêm de fora. Como resultado, a variedade e a diversidade desses setores localizados próximos, ao contrário dos setores especializados e geograficamente concentrados, promovem inovação e crescimento (Glaeser et al., 1992; Greunz, 2002; Panne, 2004).

As externalidades de diversificação consistem na troca complementar de conhecimento através de diversas firmas e agentes econômicos que facilitam a busca e os experimentos na inovação. A estrutura de indústrias diversificadas locais conduz ao aumento de retornos e a diversificação das externalidades. A evidência empírica do efeito da composição da atividade econômica sobre a inovação tem produzido resultados mistos.

Trabalhos de Das e Finne (2008), Ejermo (2005) e Panne (2004) para regiões da Noruega, Suécia e Holanda, respectivamente, mostraram que uma estrutura econômica especializada em alguns setores é mais favorável à inovação, ainda que tais resultados possam estar vinculados à intensidade tecnológica dos setores, particularmente nos dois primeiros países. Resultado similar a esses podem ser encontra- 
dos em Koo (2005), que afirma ser a especialização conducente à inovação, principalmente em setores intensivos em tecnologia, nos quais os transbordamentos de conhecimento são mais propensos a ocorrer.

Por outro lado, Carlino et al. (2007), Co (2002) e Fritsch e Franke (2004) encontraram evidência favorável a uma estrutura industrial diversificada para áreas metropolitanas e Estados norte-americanos e regiões alemãs, respectivamente. Outros trabalhos mostram que ambos os tipos de externalidades são importantes para explicar a inovação, como no caso de setores de alta tecnologia de regiões europeias (Greunz, 2004).

Paci e Usai (2000) argumentam que a evidência empírica mista pode estar relacionada à ausência de uma base de dados pela qual se possa discriminar adequadamente entre os dois tipos de externalidades. Os autores, ao utilizarem o quociente locacional para medir grau de especialização e a recíproca do índice de Gini para o grau de diversificação, encontraram que ambos os tipos de externalidades são determinantes relevantes da inovação italiana.

Na Espanha, as externalidades do tipo MAR são mais favoráveis à promoção de inovações que as externalidades de diversificação. Estas últimas somente se tornam relevantes quando se considera a origem dos transbordamentos de P\&D ou seus efeitos a partir da combinação da origem com o nível de desenvolvimento alcançado pela região (Cabrer-Borrás e Serrano-Domingo, 2007). Koo (2007) afirma que a importância relativa dos dois tipos de externalidades depende de quão intensiva em conhecimento é a indústria.

Ao nível médio de intensidade de conhecimento, ambas, diversidade e especialização, são positivamente associadas à ocorrência de transbordamentos tecnológicos localizados. Essa importância diminui quando a intensidade de conhecimento da indústria aumenta. Por outro lado, a importância da especialização de empresas que compartilham a mesma base de conhecimento aumenta à medida que cresce a intensidade de conhecimento da indústria.

No caso brasileiro, há evidências que favorecem a hipótese de diversificação industrial de microrregiões (Gonçalves e Almeida, 2009). Entretanto, o objetivo principal desse artigo foi o de testar a existência de transbordamentos de conhecimento tecnológico no Brasil, 
a partir da estrutura da função de produção de conhecimento de Griliches (1979), modificada por incorporar algumas variáveis de controle. Como o Brasil é um país de dimensões continentais e caracterizado por grande grau de heterogeneidade econômica entre seus diversos Estados, é possível que haja diferenças substanciais quando a análise foca especificamente alguns sistemas regionais de inovação do País. Logo, o objetivo deste artigo é testar a hipótese de Marshall (1982) e a hipótese de Jacobs (1969) nas microrregiões de São Paulo, analisando especialmente o impacto das externalidades de diversificação ou especialização sobre a capacidade regional de inovar.

O Estado de São Paulo é o principal centro econômico do país, não somente pela concentração de atividades industriais e de instituições financeiras, mas também pela presença de sede de grandes grupos nacionais e internacionais, além de ampla infraestrutura urbana e de pesquisa. Por isso, seu estudo permite identificar também as principais características do sistema de inovação brasileiro.

O artigo usa uma base de dados que cobre todos os anos do período compreendido entre 1996-2003 para 63 microrregióes do Estado de São Paulo. Desse modo, é possível realizar uma investigação espacial e temporal do progresso do sistema inovador de São Paulo, com métodos de estimação de dados em painel que tratam da dependência espacial. Embora tais métodos venham sendo utilizados de forma crescente, pode-se constatar que a literatura da área ainda usa predominantemente métodos com dados em cross-section nos trabalhos empíricos (Quadro 1). 


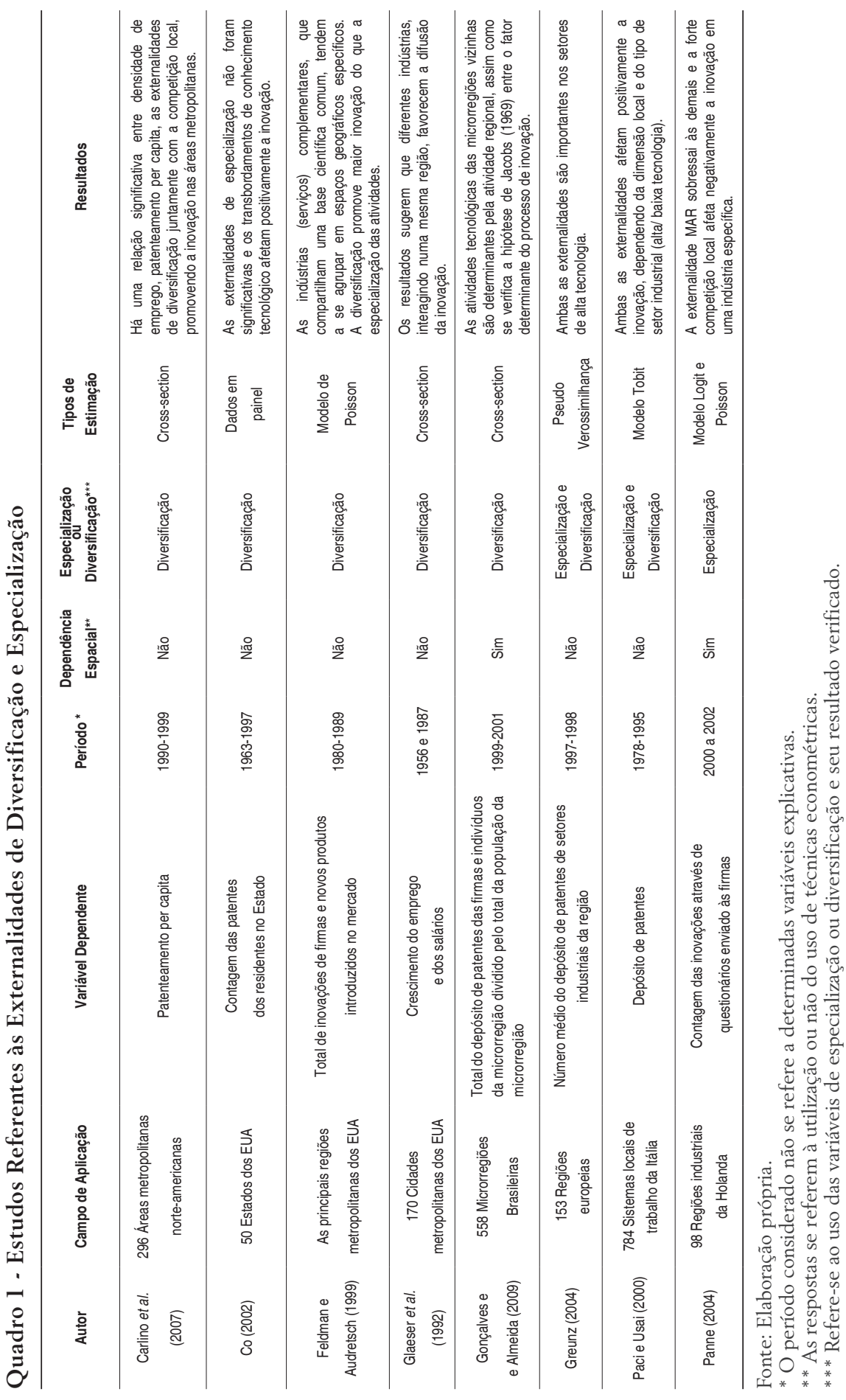




\section{Principais Características da Atividade Inovativa em São Paulo}

A capacidade de gerar e assimilar inovações é considerada bastante heterogênea, sendo predominante nas macrorregiões brasileiras dotadas de melhor infraestrutura científica e tecnológica (Diniz e Gonçalves, 2005). De modo geral, o Estado de São Paulo destaca-se frente às outras regiões pelo sistema público de ciência e tecnologia (C\&T), que é o mais diversificado e desenvolvido entre os sistemas do País. Do mesmo modo, a grande participação em produção científica e a concentração de pesquisadores domiciliados em São Paulo indicam relevante atividade científica, justificada tanto pela presença de diversas universidades (públicas e privadas) tanto pelo papel desempenhado pelos docentes no sistema de educação superior e no sistema de pesquisa nacional (Quadros et al., 2001).

Por isso, a dinâmica inovadora do Brasil está fortemente vinculada ao Estado de São Paulo (Figura 1). Em termos de indicadores de inovação, estima-se que este concentra $58 \%$ dos gastos de $\mathrm{P} \& \mathrm{D}$ das empresas brasileiras que inovam e realizam esse tipo de dispêndio (PINTEC, 2005), 44\% das patentes depositadas no Instituto Nacional de Propriedade Industrial (INPI, 2006), 41,5\% das patentes depositadas no USPTO$^{1}$ (Albuquerque et al., 2005) e 61\% do valor agregado de firmas brasileiras consideradas inovadoras de produto que exportam com preço-prêmio (Gonçalves, 2007b).

Em termos de indicadores vinculados à atividade industrial, São Paulo concentra 39\% do valor agregado da indústria brasileira (PIA, 2006) e $37 \%$ do pessoal ocupado total (PIA, 2006). Em termos de profissionais vinculados a áreas de formação tecnológica, como Química, Física, Ciências Biológicas e de saúde animal, Engenharias e Informática, a concentração total do Estado é notável, cerca de 44\% em relação ao país (RAIS, 2006). A rede de ensino e pesquisa está distribuída de forma heterogênea em termos regionais, favorecendo, também, o Estado de São Paulo, que contém 24\% das instituições de ensino, 24\% dos professores, $23 \%$ dos professores com mestrado e $32 \%$ dos professores com título de doutor. (INEP, 2008).

Grande parte dessa concentração da atividade inovadora pode ser explicada pela concentração prévia de atividade econômica e pela composição diversificada da estrutura industrial do Estado, as quais

${ }^{1}$ United States Patent and Trademark Office 
possuem raízes históricas destacadas por Cano (1977). Segundo o autor, a configuração da estrutura industrial do Estado de São Paulo deve-se, em grande parte, ao processo histórico de formação da indústria brasileira e ao papel de destaque que este teve na sua constituição e origem. O autor destaca que o processo de concentração da produção industrial revela dois momentos importantes ao crescimento econômico do Estado.

O primeiro momento, chamado de concentração por estímulo, compreende o período da primeira guerra mundial, quando a produção paulista cresce, em grande parte atendendo à demanda do resto do país. No segundo momento, década de 1920, a expansão da produção paulista cresce, concentrando-se por necessidade, quer dizer, a conquista de mercados externos depende desse processo de acumulação prévia.

Logo, os efeitos do dinamismo industrial em São Paulo podem ser explicados pela sua própria economia, que constituíram uma base sólida de condições propícias ao processo de concentração industrial. $\mathrm{O}$ resultado desse processo foi a formação de uma estrutura produtiva completa e integrada, responsável por uma parcela significativa da produção industrial do país.

A importância econômica e inovativa de São Paulo deve-se à presença de diferentes setores industriais e à sua capacidade de atração de novos investimentos, sendo considerado um grande centro irradiador da industrialização para as demais regiões do Brasil (Lemos et al., 2005). A microrregião de São Paulo e suas adjacências despontam como o principal centro econômico do país, tanto pela presença e concentração de atividades industriais, de serviços modernos, de instituições financeiras, de sedes de grandes grupos nacionais e de corporações multinacionais quanto pela excelente infraestrutura e amenidades urbanas. A riqueza e magnitude destas economias de aglomeração explicam a alta atividade tecnológica presente na região.

Pelo mapa dos percentuais da média das patentes per capita (Figura 1) também é possível observar a concentração e o percentual das patentes de cada microrregião. Destacam-se as regiões assinaladas no mapa: São Carlos (1), Rio Claro (2), Piracicaba (3), Amparo (4), Jundiaí (5), Itapecerica da Serra (6) e São Paulo (7). 


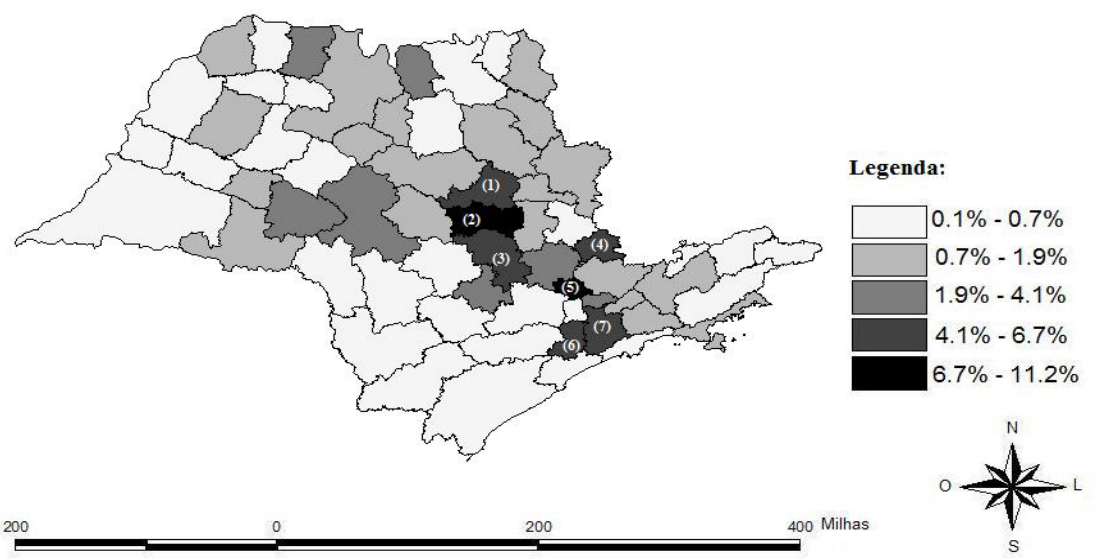

Fig.1 - Mapa da Média das Patentes per capita (\%) (1996-2003) Fonte: Elaboração própria.

Entretanto, ainda que a microrregião de São Paulo (7) concentre 58\% do estoque de depósitos de patentes do período 1996-2003, a força do Estado não se resume exclusivamente à sua capital ou área metropolitana. Sua importância é caracterizada pela existência de uma rede urbana equilibrada, na qual várias cidades de porte médio são bem interligadas por excelentes rodovias.

Tais cidades destacam-se pela qualidade de sua infraestrutura urbana e pela presença de uma ampla e sofisticada rede de ensino e pesquisa. Isso contribui para que haja transbordamentos de conhecimento tecnológico no interior do próprio Estado, como caracterizado por Gonçalves (2007a), que identifica nas regiões Sudeste e Sul grande parte dos padrões espaciais de inovação definidos pelo regime Alto-Alto segundo o método de análise exploratória espacial, ou seja, regiões com alta concentração de inovação são vizinhas de outras que também possuem grande concentração de inovação, medidas por patentes per capita.

Gonçalves (2007a) afirma que a qualidade da vizinhança é fator essencial para o processo de transbordamento tecnológico. Logo, baixos índices de industrialização, de escolaridade da população adulta, de doutores, de empregados com formação tecnológica, de diversidade tecnológica e uma estrutura industrial concentrada em poucas empresas funcionam como barreiras ao processo de difusão espacial da 
atividade tecnológica entre as microrregiões brasileiras, medida por patentes. Essas barreiras espaciais impedem que transbordamentos de conhecimento operem, difundindo inovações entre microrregiões vizinhas. No caso brasileiro, essas barreiras parecem inexistir no interior da grande aglomeração espacial tecnológica do Estado de São Paulo e das aglomerações Porto Alegre-Caxias do Sul-Passo Fundo e Blumenau-Joinville-Itajaí-Florianópolis e de Curitiba e adjacências. Outras localidades importantes são: Campinas, São José dos Campos e São Carlos, que também podem ser chamadas de pólos tecnológicos. Essas regiões merecem destaque, pois possuem liderança no depósito de patentes do Instituto Nacional da Propriedade Industrial (INPI), pelo fato de abrigarem instituições como a Universidade Estadual de Campinas (UNICAMP), o Centro de Tecnologia da Aeronáutica (CTA) e a Empresa Brasileira de Pesquisa Agropecuária - EMBRAPA (Albuquerque et al., 2005).

A região de Campinas é caracterizada por um conjunto de empresas que atuam em setores de alta tecnologia. Além disso, a localidade conta com a presença de duas grandes universidades: a Universidade Estadual de Campinas (UNICAMP) e a Pontifícia Universidade Católica de Campinas (PUCCAMP) e diversos institutos de pesquisa como o Instituto Agronômico de Campinas (IAC), o Centro de Tecnologia e Informática (CTI) e o Centro de Pesquisa e Desenvolvimento (CPqD/Telebrás) (Souza e Garcia, 1999).

Já na região de São José dos Campos pode-se observar a existência de uma ampla infraestrutura de ciência e tecnologia, que se traduz na presença de organismos como a Universidade do Vale do Paraíba (UNIVAP), o CTA e o Instituto Nacional de Pesquisas Espaciais (INPE). Além disso, a presença de filiais de multinacionais e empresas do setor bélico e aeroespacial, como a Empresa Brasileira de Aeronáutica S.A. (EMBRAER) e o Instituto Tecnológico da Aeronáutica (ITA).

A região de São Carlos, igualmente aos outros pólos tecnológicos citados anteriormente, conta com uma ampla infraestrutura de ciência e tecnologia, no qual estão incluídos dois centros de pesquisa da EMBRAPA e duas universidades públicas, a Universidade de São Paulo (USP) e a Universidade Federal de São Carlos (UFSCar). A rede urbana do Estado de São Paulo também influenciou a tendência de reaglomeração produtiva brasileira a partir dos anos 70 , em que a 
perda relativa de produção da área metropolitana de São Paulo deu lugar a um processo de "desconcentração concentrada".

Diniz (1994) afirma que o caso brasileiro é chamado de desenvolvimento poligonal. Por meio desse processo particular de descentralização, um número limitado de crescimento de novos pólos ou regiões tem captado maiores parcelas de novas atividades econômicas, especialmente as regiões próximas a São Paulo, o que tem dificultado um amplo processo de desconcentração econômica.

Após essa breve descrição do sistema regional de inovação do Estado mais desenvolvido do Brasil, o objetivo das próximas seções do artigo será o de revelar a influência de externalidades decorrentes de uma estrutura industrial completa e integrada sobre a produção de inovações. Mais especificamente, serão avaliados os efeitos da existência de uma estrutura diversificada vis-à-vis uma estrutura especializada em alguns setores industriais sobre a ocorrência de inovações.

\section{Modelo Empírico}

\subsection{Aspectos Metodológicos}

A análise dos determinantes da inovação tem por base a estrutura teórica da função de produção do conhecimento desenvolvida por Griliches (1979) e estendida por Cabrer-Borrás e Serrano-Domingo (2007), incluindo variáveis de controle. Entretanto, ao contrário desse trabalho, procura-se levar em consideração métodos que controlam a endogeneidade oriunda da inclusão da variável dependente defasada no tempo como variável explicativa, para capturar o efeito da trajetória pré-estabelecida (path-dependence).

A expansão do modelo permitiu levar em consideração a difusão do conhecimento ao longo do tempo e os esforços de P\&D da economia local do ano anterior que poderiam gerar transbordamentos de conhecimento locais, favorecendo a inovação local.

A estrutura industrial da região, se especializada ou diversificada, também pode influenciar a capacidade de inovação regional. A análise leva em consideração a presença das externalidades de especialização (Glaeser et al., 1992) e de diversificação (Jacobs, 1969) e, com 
isso, pretende-se observar os efeitos dessas variáveis sobre as regiões. Logo, a geração da inovação pode ser formalizada abaixo:

$$
I_{t}=f\left(I_{t-1}, E_{t}, P D_{t-1}, S_{t}, D_{t}\right)
$$

onde $I_{t}$ representa a inovação gerada na microrregião i no período $t$, enquanto que $I_{t-1}$ é caracterizado como as inovações defasadas em um período, influenciando a atividade inovativa na região no período corrente; $E_{t}$ denota a dotação de capital humano das regiões, $P D_{t-1}$ indica os esforços de $\mathrm{P} \& \mathrm{D}$ da região no período imediatamente anterior. Por sua vez, $D_{t}$ representa as externalidades de diversificação, enquanto que $S_{t}$ as externalidades de especialização.

O modelo leva em consideração dois aspectos do conhecimento tecnológico como seu caráter parcialmente público e sua apropriabilidade não perfeita. Então, o conhecimento tecnológico pode transbordar, mas sua difusão é geograficamente localizada.

Do ponto de vista empírico, usando a notação de dados empilhados, segue abaixo a regressão a ser estimada:

$$
I_{t}=\delta I_{t-1}+\beta_{1} P D_{t-1}+\beta_{2} E_{t}+\beta_{3} D_{t}+\beta_{4} S_{t}+\alpha+\varepsilon_{t}
$$

em que $I_{t}=\left(I_{1 t}, \ldots, I_{N t}\right)^{\prime}$ é o vetor de patentes per capita sendo a pro$x y$ para a inovação; $\alpha=\left(\alpha_{1}, \ldots, \alpha_{N}\right)^{\prime}$ representa o vetor de efeitos não observados; $I_{t-1}=\left(I_{1, t-1}, \ldots, I_{N, t-1}\right)^{\prime}$ denota o vetor de patentes per capita defasado temporalmente; $P D_{t-1}=\left(P D_{1, t-1}, \ldots, P D_{N, t-1}\right)^{\prime}$ é o vetor de dados da capacidade de P\&D; $E_{t}=\left(E_{1 t}, \ldots, E_{N t}\right)^{\prime}$ é o vetor contendo os dados de escolaridade da população; $D_{t}=\left(D_{1 t}, \ldots, D_{N t}\right)^{\prime}$ representa o vetor de dados de externalidades de diversificação; $S_{t}=\left(S_{1 t}, \ldots, S_{N t}\right)^{\prime}$ é o vetor de especialização; por sua vez, $\varepsilon_{t}=\left(\varepsilon_{1 t}, \ldots, \varepsilon_{N t}\right)^{\prime}$ é o vetor de termo de erros independentes e identicamente distribuídos. Finalmente, $\delta, \beta_{1}$ , $\beta_{2}, \beta_{3}$ e $\beta_{4}$ são coeficientes a serem estimados.

Johnston e Dinardo (1997) consideram que o modelo de dados em painel é útil porque é capaz de lidar com o problema de variáveis omitidas. Isto significa, também, que o modelo de dados em painel pode acomodar a heterogeneidade espacial que é representada por regiões específicas, não observáveis e com interceptos de tempo que não variam. Logo, os dados em painel controlam dois efeitos não ob- 
serváveis por meio de dois diferentes modelos: um modelo de efeitos fixos e um modelo de efeitos aleatórios.

A diferença entre esses dois modelos repousa no pressuposto sobre a correlação dos efeitos não observados $(\alpha)$ com o termo de erro $\left(\varepsilon_{t}\right)$. $\mathrm{Se}$, ao menos, os efeitos não observados são correlacionados com o termo de erro, o modelo de efeito fixo é mais apropriado. No entanto, se os efeitos não observados não forem correlacionados ao termo de erro, considera-se o modelo de efeitos aleatórios como mais apropriado. Neste caso, os efeitos não observáveis são componentes do termo de erro.

Neste trabalho, as considerações teóricas demandam que a defasagem temporal, $I_{t-1}$, seja incluída no lado direito da regressão. Neste contexto, a Equação (2) representa o modelo dinâmico de dados em painel. Além disso, o uso de dados regionais pode conter a dependência espacial (Anselin, 1988; Anselin e Bera, 1998). Se a dependência espacial não for levada em consideração, os coeficientes estimados da regressão podem ser inconsistentes e/ou ineficientes. Por exemplo, na literatura a respeito da função de produção de conhecimento, considera-se que a variável dependente defasada espacialmente como um regressor potencial a fim de captar transbordamentos espaciais (Gonçalves e Almeida, 2009; Moreno et al., 2004). Além da variável dependente defasada espacialmente, a dependência espacial pode, ainda, ser manifestada na forma de variáveis independentes defasadas espacialmente e/ou termos de erros defasados espacialmente (Anselin, 2003).

No modelo de dados em painel dinâmico espacial pode haver duas fontes de endogeneidade. A primeira é a endogeneidade temporal, porque a variável dependente defasada em um período é correlacionada com o termo de erro. A segunda fonte de endogeneidade é representada pela eventual presença da defasagem espacial da variável dependente.

Como é conhecido pela literatura, na presença de endogeneidade as estimações pelo método dos Mínimos Quadrados Ordinários (MQO) são enviesadas e inconsistentes. Além disso, Cameron e Trivedi (2005) demonstram que os estimadores tradicionais de efeitos fixos também não são consistentes. Como salientado por Cameron e Trivedi (2005), mesmo que os efeitos não observados sejam alea- 
tórios, existe o problema da endogeneidade. Isto porque a variável dependente defasada em um período é correlacionada com os efeitos aleatórios e, consequentemente, com a composição do termo de erro.

Em virtude disso, a fim de estimar consistentemente este tipo de modelo é necessário superar três obstáculos. Primeiro, faz-se necessário remover os efeitos não observáveis. Segundo, a endogeneidade temporal precisa ser tratada adequadamente. Finalmente, é necessário lidar com a endogeneidade espacial. O primeiro problema é resolvido usando os tradicionais estimadores de modelos de dados dinâmicos espaciais, como o estimador Arellano-Bond (1991) ou o estimador Blundell-Bond (1998). O estimador Arellano-Bond (1991) transforma a Equação original (2), extraindo as diferenças e, posteriormente, estimando pelos Métodos Generalizados dos Momentos (MGM), usando a variável dependente defasada em três ou mais períodos como instrumentos.

O problema com o estimador Arellano-Bond (1991) é que se os dados tiverem uma grande persistência temporal ( $\delta$ próximo a um), esses instrumentos baseados nas defasagens temporais da variável dependente serão fracos instrumentos para a equação transformada. Para contornar isso, Blundell e Bond (1998) sugerem a adoção do MGM sistêmico como método de estimação, no qual num sistema de equações composto pela regressão em nível e pela regressão em diferenças é estimado pelos métodos generalizados dos momentos (Baltagi, 2008; Cameron e Trivedi, 2005; Blundell e Bond, 1998).

O problema com a dependência espacial contido na Equação (2) precisa ainda ser tratado adequadamente. Na literatura, Badinger et al. (2004) foram os primeiros autores a proporem um procedimento indireto para estimar modelos de painel de dados dinâmicos espaciais. O procedimento é simples e baseia-se em duas etapas, que envolvem primeiro a filtragem espacial das variáveis para remover a correlação espacial e a aplicação tradicional dos estimadores MGM para modelos dinâmicos na segunda etapa (Badinger et al., 2004).

Neste tipo de estimação, o ponto crucial reside no fato de como filtrar espacialmente as variáveis da regressão. O procedimento proposto por Badinger et al. (2004) adota a filtragem espacial desenvolvida por Getis e Griffith (2002). Para exemplificar a filtragem espacial, considera-se qualquer variável sob estudo, quer dizer $y$ : 


$$
y^{*}=y \frac{E\left(G_{i}(d)\right)}{G_{i}(d)}
$$

onde $E\left(G_{i}(d)\right)$ é o valor esperado das estatística local de Getis-Ord, $G_{i}(d)$.

$$
y_{i}^{*}=y_{i} \frac{\left(\sum_{j} w_{i j}(d) /(N-1)\right)}{G_{i}(d)}
$$

Nota-se que a estatística local de Getis-Ord é definida como:

$$
G_{i}(d)=\frac{\sum_{j} w_{i j}(d) y_{j}}{\sum_{j} y_{j}}
$$

onde $\mathrm{w}_{\mathrm{ij}}(\mathrm{d})$ é uma matriz de ponderação espacial baseada em pesos binários definidos pela distância. Vale ressaltar que a Equação (3) expressa a relação entre o valor esperado de $G_{i}(d)$, no qual indica que não existe dependência espacial na região i. Essa relação fornece a magnitude local da dependência espacial. A multiplicação desta razão com o valor real da observação i permite a filtragem espacial desta variável. A variável filtrada é caracterizada por $\mathrm{y}_{\mathrm{i}}{ }^{*}$.

Existem três inconvenientes com essa filtragem espacial. Primeiro, a filtragem leva em consideração somente a autocorrelação espacial positiva, uma vez que a estatística $\mathrm{G}_{\mathrm{i}}(\mathrm{d})$ seja um indicador de concentração, capturando somente Alto-Alto (hot spots) e Baixo-Baixo (cool spots). Consequentemente, a autocorrelação negativa não é removida dessas variáveis. Segundo, essa filtragem pode ser implementada com variáveis que contenham valores positivos, fornecidos por $\mathrm{G}_{\mathrm{i}}(\mathrm{d})$ que é calculado somente para valores estritamente positivos. Por último, se implementada com a estatística $\mathrm{G}_{\mathrm{i}}(\mathrm{d})$, proposta por Getis e Ord (1992), a matriz de pesos espaciais deve ser baseada em pesos binários definidos pela distância. Contudo, esses tipos de matrizes limitam a especificação do arranjo de interação espacial. ${ }^{2}$

\footnotetext{
${ }^{2}$ Ord e Getis (1995) propuseram uma nova versão da estatística G, em que essa limitação é superada.
} 
Levando em consideração essas desvantagens, outra forma de filtragem espacial é proposta no presente trabalho. Esse outro tipo de filtragem é baseado na estatística local do I de Moran (Anselin, 1995). A razão para isso repousa no fato da estatística não sofrer as limitações referentes ao $\mathrm{G}_{\mathrm{i}}(\mathrm{d})$.

A filtragem é expressa como:

$$
y^{*}=y \frac{E\left(I_{i}\right)}{I_{i}}
$$

onde $\mathrm{E}\left(\mathrm{I}_{\mathrm{i}}\right)$ é o valor esperado da estatística do I de Moran local quando se assume que não existe autocorrelação espacial. A ideia subentendida pela filtragem é a mesma da filtragem espacial proposta por Getis e Griffith (2002). A razão entre o valor esperado de $I_{i}$, que indica a não existência de dependência espacial na região ${ }_{i}$, e o valor calculado de $\mathrm{I}_{\mathrm{i}}$, usa os dados observados da variável y. Multiplicando esta razão e os valores observados $\mathrm{y}_{\mathrm{i}}$, remove-se a autocorrelação espacial das variáveis, filtrando-as também. ${ }^{3}$

Logo, a estratégia para a estimação do modelo de dados dinâmicos espaciais com variáveis filtradas espacialmente segue os seguintes passos:

a) Filtram-se espacialmente as variáveis;

b) Aplica-se o estimador Arellano-Bond no sistema de equações com as variáveis filtradas espacialmente.

\subsection{Base de Dados}

A base de dados foi construída a partir da conjugação de diferentes fontes, como microdados referentes ao valor de transformação industrial (VTI) de firmas industriais da Pesquisa Industrial Anual (PIA), dados de patentes do INPI, dados de empregos da RAIS e dados de

\footnotetext{
${ }^{3}$ Para a seleção da matriz de pesos espaciais utilizada no cálculo, foi adotado o procedimento de Baumont (Baumont, 2004).
} 
matrículas em ensino superior da Fundação SEADE. Os dados foram organizados em microrregiões geográficas do Estado de São Paulo, totalizando 63 unidades de observação que foram acompanhadas no período 1996-2003. Estatísticas descritivas de todas as variáveis, assim como a matriz de correlação de Pearson, podem ser encontradas nos Anexos 1 e 2, respectivamente. A matriz de correlação revela baixa correlação parcial entre as variáveis explicativas, o que não deve acarretar problemas de multicolinearidade na regressão. A variável dependente $\left(I_{t}\right)$ expressa o número de depósitos de patentes das microrregiões, segundo o INPI, dividido pelo total da população das microrregiões, tendo como base a contagem da população de 2006, o censo de 2000 e as estimativas populacionais para os outros anos do período. Essa variável representa uma proxy da capacidade de inovação ou da atividade tecnológica das microrregiões e segue a literatura da área (Moreno et al., 2004; Carlino et al., 2007).

Segundo Breschi (1998) e Bosch et al. (2005), as patentes seriam boas indicadoras da performance tecnológica regional, permitindo a investigação dos determinantes do processo local de inovação. $\mathrm{O}$ INPI conta com 25.930 registros de patentes para o Estado de São Paulo no período 1996-2003 que possuíam endereço do primeiro inventor da patente. A residência do inventor foi usada, ao invés do endereço do titular da patente, por causa do objetivo de identificar o potencial regional de invenção.

A defasagem temporal da inovação $\left(I_{t-1}\right)$ representa o total de depósito das patentes das microrregióes dividido pelo total de sua população, ambos defasados temporalmente pelo período de um ano. Conforme Ejermo (2005), o uso do período anterior da variável dependente supõe que o atual desenvolvimento da inovação de produtos e processos deve ser analisado como dependente das inovações anteriores. Isso permite incorporar a ideia de que a produção tecnológica regional é dependente de uma trajetória preestabelecida (path-dependence), nos termos formulados por Arthur (1989).

A capacidade de realização de $\mathrm{P} \& \mathrm{D}$ representada pela variável $\left(P D_{t-1}\right)$ é definida como sendo a proxy dos gastos da microrregião com $\mathrm{P} \& \mathrm{D}$, a saber, o número de empregados com formação tecnológica, defasados temporalmente em um ano, dividido pelo total de empregados da microrregião da RAIS. A proxy para capacidade empresarial de realizar P\&D será obtida pela quantidade de empregados com forma- 
ção em Física, em Química, em Engenharias, em Análise de Sistemas e Programação, segundo a RAIS.

Conforme Diniz e Gonçalves (2005), a escolha por determinadas profissões deve-se ao fato de haver relevância em termos de possibilidade de transferência de novas técnicas para o setor produtivo. O objetivo desta variável é verificar o impacto da capacidade prévia de realizar P\&D sobre a atividade inovativa atual, mais especificamente, capturar a causalidade entre a capacidade de realizar P\&D do passado e a produção tecnológica atual da região (Bode, 2004).

Quanto ao índice de especialização industrial $\left(S_{t}\right)$ sua fórmula pode ser representada como:

$$
S_{t}=\left(\frac{1}{2}\right) \sum_{i}\left|\left(V T I_{i j} / V T I_{i}\right)-\left(V T I_{N j} / V T I_{N}\right)\right|
$$

onde $i$ representa microrregião, $j$ o VTI do setor industrial, e $N$ o valor total do VTI do setor industrial. Tal variável possui uma variação de zero a um, sendo interpretado de maneira que quanto mais próximo da unidade, maior o grau de especialização em atividades ligadas a um determinado setor industrial. Ao contrário, quanto mais próximo de zero, sua composição industrial será uniforme em todas as microrregiões (Cabrer-Borrás e Serrano-Domingo, 2007). O coeficiente positivo indica que há uma especialização regional de uma determinada indústria, o que facilita os transbordamentos de conhecimento entre as firmas do mesmo setor industrial e a atividade local inovativa, corroborando a hipótese de externalidades MAR (Cabrer-Borrás e Serrano-Domingo, 2007).

O índice de diversificação $\left(D_{t}\right)$ que representa o grau de diversificação dos setores industriais será construído por intermédio do Índice de Herfindhal-Hirschman. Sua fórmula é representada por:

$$
D_{t}=\sum_{j}\left(V T I_{i j} / V T I_{i}\right)^{2}
$$

O índice mede a diversidade industrial das microrregiões por intermédio do VTI dos setores industriais da Classificação Nacional de Atividades Econômicas (CNAE) a três dígitos do IBGE. O índice 
varia de zero a um, sendo que quanto mais próximo de zero, maior é o grau de diversidade das indústrias existentes na microrregião.

A variável tem por objetivo identificar o impacto do grau de diversificação industrial sobre a atividade tecnológica regional. De acordo com Jacobs (1969), quanto mais diversificada a estrutura industrial, mais inovativa ela será. Por causa da forma pela qual o indicador é construído, o sinal empírico esperado para essa variável é negativo (Quadro 2). Desse modo, como existem duas medidas para os graus de especialização e diversificação, tais indicadores não são mutuamente exclusivos, pois uma microrregião pode conter setores industriais especializados e, ao mesmo tempo, ser uma região diversificada (Koo, 2005). Segundo Paci e Usai (2000), usar dois indicadores para captar graus de especialização e diversificação é um passo à frente em relação aos trabalhos que usam apenas um indicador, como o índice de Herfindhal, para representar os dois fenômenos.

Os autores afirmam que o grau de especialização é um aspecto referente ao setor econômico de determinado sistema produtivo local, enquanto que o grau de diversidade refere-se ao território como um todo. Logo, é possível haver inúmeras combinações possíveis entre níveis diferentes de especialização de um setor e graus de diversidade da área em que tais setores estão localizados. Para os índices de especialização e diversificação, a base da PIA foi utilizada para a obtenção do VTI a três dígitos da Classificação Nacional de Atividades Econômicas (CNAE), totalizando 101 grupos industriais da indústria de transformação brasileira. ${ }^{4}$ Em relação ao grau de agregação dos dados setoriais para construção dos índices de especialização e diversificação, Beaudry e Schiffauerova (2009) revelam que os resultados podem ser sensíveis a esse procedimento.

O uso de dados pouco desagregados (dois dígitos, por exemplo) favorece a hipótese MAR, enquanto que o uso de dados mais desagregados (quatro dígitos) favorece a hipótese de Jacobs. Nesse trabalho, índices construídos a 2, 3 e 4 dígitos são calculados sem que os resultados sofram mudanças substanciais em função do grau de agregação. Logo, optou-se por apresentar os resultados sob a agregação setorial de 3 dígitos.

\footnotetext{
${ }^{4}$ Para maiores informações sobre a CNAE com suas respectivas classificações, consultar o site do IBGE (http://wwwl.ibge.gov.br/concla/).
} 
Para o nível de escolaridade $\left(E_{t}\right)$ será utilizada como proxy de escolaridade a divisão entre as pessoas matriculadas em instituições de ensino superior e a população total da microrregião. A fonte desses dados é a Fundação Sistema Estadual de Análise de Dados (SEADE). A ideia é avaliar o papel da dotação de capital humano sobre a atividade tecnológica regional. É notório que firmas com maior conteúdo tecnológico demandem mão de obra mais qualificada. Dessa forma, as firmas que empregam trabalho mais qualificado têm mais condições de diferenciar produtos e melhorar sua competitividade (De Negri et al., 2005). ${ }^{5} \mathrm{Na}$ proxy para a escolaridade $\left(E_{t}\right)$ foi usada a fonte de dados da Fundação SEADE, disponível no próprio sítio da fundação. ${ }^{6}$

Quadro 2 - Resumo das Variáveis na Análise do Sistema Inovativo das Microrregiões Paulistas

\begin{tabular}{|c|c|c|c|c|c|c|}
\hline Variável & Descrição & $\begin{array}{l}\text { Sinal } \\
\text { Teórico }\end{array}$ & $\begin{array}{l}\text { Sinal } \\
\text { Esperado }\end{array}$ & Referencial Teórico & $\begin{array}{l}\text { Referencial } \\
\text { Empírico }\end{array}$ & Fonte \\
\hline $\mathrm{I}_{\mathrm{t}}$ & $\begin{array}{l}\text { Depósito de patentes } \\
\text { dividido pela população }\end{array}$ & & & Griliches (1990) & Ejermo (2005); Greunz (2004). & INPI \\
\hline $\mathrm{I}_{\mathrm{t}-1}$ & $\begin{array}{l}\text { Defasagem temporal da } \\
\text { variável dependente }\end{array}$ & + & + & Arthur (1989) & $\begin{array}{l}\text { Cabrer-Borrás e Serrano-Domingo (2007); } \\
\text { Ejermo (2005). }\end{array}$ & INPI \\
\hline$P D_{t-1}$ & $\begin{array}{l}\text { Capacidade de } \\
\text { realizar P\&D }\end{array}$ & + & + & Jaffe (1989) & $\begin{array}{l}\text { Panne (2004); Co (2002); Audretsch e } \\
\text { Feldman (1996); Cabrer-Borrás e Serrano- } \\
\text { Domingo (2007); Feldman e Florida (1994); } \\
\text { Acosta e Coronado (2003); Fritsch e Franke } \\
\text { (2004); Acs e Audretsch (1989); Anselin } \\
\text { et al. (1997). }\end{array}$ & RAIS \\
\hline $\mathrm{S}_{\mathrm{t}}$ & Índice de especialização & + & + & $\begin{array}{c}\text { Marshall (1982); } \\
\text { Arrow (1962); } \\
\text { Romer (1986) } \\
\text { Glaeser et al (1992) }\end{array}$ & $\begin{array}{l}\text { Cabrer-Borrás e Serrano-Domingo (2007); } \\
\text { Feldman e Audrestch (1999); Moreno et } \\
\text { al. (2005); Greunz (2004); Glaeser et al. } \\
\text { (1992); Panne (2004); Das e Finne (2008); } \\
\text { Paci e Usai (2000); Koo (2005; 2007); } \\
\text { Carlino et al. (2007). }\end{array}$ & PIA \\
\hline$D_{t}$ & $\begin{array}{c}\text { Índice de } \\
\text { diversificação }\end{array}$ & + & - & Jacobs (1969) & $\begin{array}{l}\text { Moreno et al. (2005); Feldman e Audretsch } \\
\text { (1999); Ejermo (2005); Cabrer-Borrás } \\
\text { e Serrano Domingo (2007); Glaeser et } \\
\text { al. (1992); Greunz (2004); Carlino et al. } \\
\text { (2007); Das e Finne (2008); Paci e Usai } \\
\text { (2000);Koo (2005; 2007); Panne (2004). }\end{array}$ & PIA \\
\hline$E_{t}$ & $\begin{array}{l}\text { Nível de } \\
\text { escolaridade }\end{array}$ & + & + & Jaffe (1989) & $\begin{array}{l}\text { Cabrer-Borrás e Serrano-Domingo (2007); } \\
\text { Audrestsch e Feldman (1996); Carlino et } \\
\text { al. (2007) Bode (2004); Bilbao-Osório e } \\
\text { Rodríguez-Pose (2004) }\end{array}$ & SEADE \\
\hline
\end{tabular}

Fonte: Elaboração própria.

\footnotetext{
${ }^{5}$ Dados sobre o estoque regional de pessoas com pelo menos 11 anos de estudo também foram utilizados na análise, mas seus resultados não são apresentados por causa da alta correlação existente entre essa proxy de $E_{\mathrm{t}}$ e a proxy da variável $P D_{t-1}$. Entretanto, os resultados não são qualitativamente afetados.

${ }^{6}$ Site do SEADE: http://www.seade.gov.br
} 


\section{Resultados Econométricos}

Antes de apresentar os resultados das estimações para o modelo de painel dinâmico espacial, é interessante comentar os processos de estimação realizados anteriormente. A partir da forma funcional da Equação 2, realizaram-se as estimações do modelo dinâmico por MQO e do modelo de efeitos fixos estimados por Least Squares Dummy Variable (LSDV).

Os resultados das estimações levam à suspeita de que efeitos não observados possam estar causando estimações tendenciosas. Os efeitos não observados podem ser modelados por meio dos efeitos fixos ou efeitos aleatórios. O teste de Hausman, no qual se rejeitou a hipótese nula de que os efeitos aleatórios são consistentes, indicou que a melhor escolha é a modelagem por efeitos fixos para o tratamento dos efeitos não observados. Os estimadores tradicionais de efeitos fixos não são consistentes na presença da endogeneidade espacial e temporal. Na presença dessas fontes de endogeneidade foi aplicado o procedimento de Badinger et al. (2004), a fim de se obter estimativas consistentes. Após a etapa de estimação por LSDV, e com base no valor da estatística de autocorrelação espacial, I de Moran, observou-se a existência de dependência espacial nos resíduos dos anos de 1998 e 2002, no nível de 5\% e 10\% de significância, respectivamente. Em consequência disso, as variáveis da regressão foram filtradas espacialmente, usando o I de Moran local, conforme descrito na seção metodológica deste artigo.

As dificuldades decorrentes da endogeneidade são apontadas por Cabrer-Borrás e Serrano-Domingo (2007) e Iara e Traistaru (2004), os quais notaram que a presença da defasagem temporal no lado direito das regressões opera como um regressor endógeno. Desse modo, com o objetivo de tratar essa endogeneidade temporal, a adoção do estimador Arellano-Bond (1991) consiste na estimação em primeiras diferenças da Equação (2) por MGM. Com isso, o método procura usar e, ao mesmo tempo, remover os efeitos específicos não observados. Um pressuposto importante é que os erros não sejam autocorrelacionados espacialmente. A Tabela 1 mostra os resultados do modelo de dados em painel dinâmico espacial (Equação 2), estimado pelo método Arellano-Bond. 
Para a condição de validade dos instrumentos usados na estimação da Tabela 1, foi realizado o teste de Sargan. Se os instrumentos são válidos, a hipótese nula de adequação dos instrumentos não deve ser rejeitada. Nesse caso, não há evidências de inadequação do conjunto de instrumentos utilizados, a saber, regressores estritamente exógenos como a inclusão das variáveis dummies anuais (1997, 1998 e 1999) e variável dependente defasada em dois períodos.

Tabela 1 - Resultados do Modelo de Dados em Painel Dinâmico Espacial

\begin{tabular}{ccc}
\hline Variável & Coeficiente & P-valor \\
\hline $\mathrm{I}_{\mathrm{t}-1}$ & 0,0022 & 0,0000 \\
& $(12,7912)$ & \\
\hline $\mathrm{PD}_{\mathrm{t}-1}$ & $4,65 \mathrm{E}-07$ & 0,8315 \\
& $(0,2129)$ & \\
\hline $\mathrm{S}_{\mathrm{t}}$ & $4,61 \mathrm{E}-05$ & 0,0000 \\
& $(5,9763)$ & \\
\hline $\mathrm{D}_{\mathrm{t}}$ & $-3,15 \mathrm{E}-05$ & 0,0000 \\
& $(-10,1627)$ & 0,0009 \\
\hline $\mathrm{E}_{\mathrm{t}}$ & 0,0155 & \\
\hline & $(3,3452)$ & 0,6452 \\
\hline
\end{tabular}

Fonte: Elaboração própria com base no software EViews 6.

Obs: Variável dependente: $\mathrm{I}_{\mathrm{t}}$;

$\mathrm{Obs}_{1}$ : Entre parênteses encontram-se as estatísticas t.

Outro fator que corrobora o ajuste do modelo foi o teste de resíduos, por intermédio do $I$ de Moran, realizado após a estimação do modelo de dados em painel dinâmico. O resultado indica que não há dependência espacial para os anos de 1999 a 2003 (Tabela 2).

Tabela 2- Teste de Autocorrelação Espacial dos Resíduos do Modelo

\begin{tabular}{lccccc}
\hline Ano & $I$ de Moran & Média & Desvio-Padrão & z-value & P-valor \\
\hline 1999 & 0,0546 & $-0,016$ & 0,0789 & 0,8966 & 0,3699 \\
2000 & 0,0292 & $-0,016$ & 0,0789 & 0,5750 & 0,5653 \\
2001 & 0,0742 & $-0,016$ & 0,0789 & 1,4554 & 0,2520 \\
2002 & $-0,1491$ & $-0,016$ & 0,0789 & $-1,6859$ & 0,1918 \\
2003 & 0,0025 & $-0,016$ & 0,0789 & 0,2360 & 0,8135 \\
\hline
\end{tabular}

Fonte: Elaboração própria com base no software SpaceStat 1.91.

Nota: A matriz de peso espacial utilizada é do tipo Queen. 
Além disso, o coeficiente da defasagem temporal não revela persistência, porque sua magnitude é muito pequena (próximo de zero). De acordo com Blundell e Bond (1998), isso significa que os instrumentos não são fracos. Logo, o estimador Arellano-Bond (1991) é apropriado para estimar o modelo de dados em painel dinâmico espacial, representado pela Equação (2). Com base nos resultados do modelo dinâmico espacial serão avaliados os determinantes da atividade inovadora das microrregiões paulistas, isto é, as influências das externalidades de diversificação e especialização, a capacidade de realizar P\&D, a escolaridade da população nas localidades.

Por intermédio da Tabela 1 observa-se que a variável que representa a inércia temporal da inovação nas microrregiões de São Paulo $\left(\mathrm{I}_{\mathrm{t}-1}\right)$ obteve sinal positivo e foi significativa no nível de $1 \%$ de significância. Tal resultado pode ser justificado por Arthur (1989) como um processo de mudança tecnológica denominado de trajetória preestabelecida (path-dependence). Isso significa que eventos históricos passados exercem uma grande influência sobre as inovações atuais, bem como sobre o aprendizado e o progresso tecnológico futuros.

Simmie (2001) afirma que a inovação possui uma tendência de ser path-dependent e que as trajetórias tecnológicas são dependentes da trajetória preestabelecida, o que significa dizer que a hegemonia regional em termos de atividade inovativa, uma vez surgida, é difícil de ser alterada. Nesse sentido, o surgimento de inovações em outras regiões pode se tornar bloqueado, em consequência da inércia inovadora criada naquela região. As patentes, os direitos autorais e/ou marcas registradas são alguns dos fatores que provocam um bloqueio (lock-in) à continuidade no processo inovativo em locais diferentes.

Logo, pode-se presumir que a inércia temporal da atividade inovativa em São Paulo é importante para o processo inovador atual. A inovação tecnológica gerada no período anterior influencia a inovação tecnológica no período corrente. No que tange à variável que representa os esforços de pesquisa e desenvolvimento defasados temporalmente $\left(\mathrm{PD}_{\mathrm{t}-1}\right)$, o sinal de seu coeficiente, ao contrário dos demais, foi não significativo. Isso pode indicar a baixa capacidade de realização de P\&D empresarial por parte das firmas brasileiras, uma vez que outros gastos com inovação, como máquinas e equipamentos e outros conhecimentos para inovar (pagamento por royalties, por exemplo) assumem posição de destaque entre as principais modalidades de gas- 
to para inovar no sistema inovador brasileiro. Mesmo contando com gastos efetivamente realizados e/ou estimados de $P \& D$, a variável que media a intensidade regional de $P \& D$ em Gonçalves (2007b) não foi estatisticamente significativa na regressão que a relacionava à ocorrência de inovações de produto em empresas exportadoras com preço prêmio, no ano 2000. Nesse trabalho, o autor mencionou que tal resultado poderia ter refletido as características do sistema de inovação brasileiro, centrado em segmentos tecnológicos de média e baixa sofisticação e pouco baseado em gastos de $\mathrm{P} \& \mathrm{D}$ internos à firma.

Ao se considerar o coeficiente da variável que representa o índice de especialização $\left(\mathrm{S}_{\mathrm{t}}\right)$, tem-se que o mesmo é positivo e altamente significativo. Esse resultado mostra que as especializações produtivas fomentam a inovação no sistema inovativo paulista. A hipótese MAR afirma que a especialização tecnológica da firmas em determinados setores propicia a inovação na região, ao lado de outras evidências empíricas revisadas anteriormente, como Ejermo (2005), Greunz (2004), Paci e Usai (2000) e Panne (2004). O resultado referente ao coeficiente do índice de diversificação $\left(\mathrm{D}_{\mathrm{t}}\right)$ possui o sinal teórico esperado, a saber, quanto menor seu valor mais diversificada é a estrutura industrial e, portanto, teoricamente (externalidades do tipo Jacobs) espera-se que haja mais inovações.

Conclui-se que, para o sistema de inovação paulista, a presença de clusters industriais especializados passa a ser um fator determinante tão relevante quanto a diversificação produtiva. Entretanto, os resultados também são coerentes com a ideia de que, mesmo em ambientes com determinadas especializações, faz-se necessária a presença de uma estrutura industrial minimamente diversificada, pois muitos fluxos interindustriais de conhecimento para inovar ocorrem na vizinhança tecnológica dos setores industriais (Pavitt, 1984). Logo, uma região que abriga uma estrutura industrial especializada e, ao mesmo tempo, diversificada possuiria, em tese, maiores chances de inovar.

No caso do sistema de inovação paulista, a especialização a três dígitos na indústria parece ser tão importante quanto o grau de diversificação para explicar a inovação. No presente trabalho, usaram-se dois indicadores distintos no sentido de atender algumas críticas da literatura empírica que afirmavam não serem mutuamente excludentes a ocorrência de indústrias especializadas e que também apresentassem algum grau de diversificação (Paci e Usai, 2000; Koo, 2007). Quanto 
à variável de escolaridade $\left(E_{t}\right)$, o seu coeficiente apresentou sinal positivo e foi significativo. Carlino et al. (2007) reconhecem que quanto maior for o nível educacional da população da região, maior será disposição para gerar e aplicar novos conhecimentos para fins econômicos. Bilbao-Osorio e Rodríguez-Pose (2004) também concordam que quanto maior o nível de escolaridade, maior a qualificação dos trabalhadores na sociedade e, portanto, maior a sua capacidade de transformar P\&D em inovação. No estudo feito por Cabrer-Borrás e Serrano-Domingo (2007), a escolaridade é um fator determinante para a inovação na Espanha. Os resultados mostraram que a inovação regional não depende somente da composição econômica do país, mas também dos esforços em P\&D e, principalmente, da qualificação da mão de obra representada pela escolaridade.

No caso brasileiro, Gonçalves e Almeida (2009) também encontraram relação positiva entre inovação e escolaridade. O resultado comprova que as inovações requerem uma força de trabalho instruída, em que a presença da população qualificada é considerada um mecanismo facilitador dos transbordamentos de conhecimento.

O sistema educacional de São Paulo é bem representado pela concentração e excelência de várias universidades públicas (UNICAMP, USP e outras) e privadas (como FGV e PUC), sendo importante para gerar recursos humanos com escolaridade superior e para conduzir pesquisa acadêmica de natureza básica e aplicada, passíveis de transferência para o setor produtivo. Quadros et al. (2001) ratificam essa questão, afirmando que a produção acadêmica e a concentração de pesquisadores de diferentes áreas tornam as instituições de ensino e pesquisa de São Paulo reconhecidas tanto nacional quanto internacionalmente.

\section{Considerações Finais}

O trabalho teve como principal objetivo a análise dos determinantes da atividade inovativa de microrregiões de São Paulo no período entre 1996-2003, dando especial ênfase ao impacto das externalidades de diversificação e especialização produtivas. $\mathrm{O}$ procedimento em dois estágios foi adotado por Bandinger et al. (2004) para estimar os modelos em painel dinâmico espaciais. Primeiro, as variáveis foram filtradas espacialmente e depois foi aplicado o estimador MGM 
convencional para estimar o modelo de painel dinâmico. Em termos metodológicos, foi proposto aqui um método diferente de filtragem espacial pelo qual se podem remover ambas as autocorrelações espaciais tanto negativa quanto positiva. Além disso, a filtragem pode ser adotada para qualquer tipo de matrizes com pesos espaciais para remover a dependência espacial contida nas variáveis da regressão.

Entre os principais resultados obtidos pela análise econométrica, verificou-se que a escolaridade, a inércia temporal da inovação, o índice de especialização e o de diversificação afetam positivamente a atividade inovadora nas microrregiões. Tais resultados propõem que as especializações e as diversificações produtivas fomentam a inovação no sistema inovador paulista, o que significa dizer que os argumentos teóricos de MAR e de Jacobs não são mutuamente excludentes.

Os resultados apurados também incitam algumas sugestões de políticas públicas relevantes ao sistema regional de inovação em São Paulo, como o fortalecimento tanto das estruturas produtivas especializadas quanto diversificadas. A análise das externalidades aponta para a necessidade de conciliar e integrar as políticas industriais e as políticas tecnológicas, tendo em vista que as inovações que ocorrem nas microrregiões do Estado de São Paulo são diretamente dependentes do grau de especialização e/ou diversificação industrial existente. Tais políticas podem ser horizontais ou verticais dependendo das especificidades dos setores.

Do mesmo modo, outro resultado que pode subsidiar políticas públicas é o relativo ao impacto da escolaridade da população local. Seria importante focar o aumento do grau de escolaridade populacional como pré-requisito para elevar a taxa de inovação regional. A esse respeito é interessante que ações sejam conduzidas no sentido de aumentar a escolaridade média da população, pois quanto maior esse indicador, mais provável é o surgimento de novas ideias que possam ser canalizadas para o setor produtivo, gerando inovações. Os resultados de dependência temporal da inovação revelam que é difícil alterar o quadro regional de inovações no Estado de São Paulo, no sentido de minimizar a concentração da inovação e os impactos que tal concentração possui sobre a participação na renda em cada microrregião do Estado. Entretanto, mesmo assim, políticas públicas podem ser orientadas no sentido de aumentar a taxa de inovação de microrregiões menos inovadoras. 
Os resultados encontrados para o Estado de São Paulo também podem, de forma indireta, subsidiar a formulação de políticas públicas em outras unidades da federação, nem sempre comparáveis em termos de pré-requisitos para a geração de inovações. Em geral, os investimentos em educação e qualificação da força de trabalho local também são prescrições válidas para outros estados brasileiros, assim como os incentivos que aumentem a taxa de inovação das firmas dos setores industriais já estabelecidos nas estruturas produtivas locais. Por outro lado, o crescimento e fortalecimento de novas aglomerações produtivas e inovativas fora do Estado de São Paulo depende de investimentos públicos que aumentem o nível de economias de aglomeração (localização e urbanização) em ambientes regionais menos favorecidos.

O problema primordial reside em recriar nas regiões periféricas de outros estados brasileiros as externalidades favoráveis à inovação que existem nas regiões mais desenvolvidas do Brasil, que geralmente estão em São Paulo. Em geral, as políticas regional e industrial possuiriam maior facilidade para atrair empresas não inovadoras para regiões desfavorecidas. De acordo com o grau de desenvolvimento da aglomeração industrial, poder-se-ia fazer uso da política industrial para identificar gargalos e possíveis fontes potenciais de externalidades de aglomeração de atividades a serem exploradas, no caso de aglomerações territoriais menos consolidadas. No caso de regiões periféricas não industrializadas, as políticas industrial e regional, conjuntamente, deveriam criar condições mínimas para atração do capital. Um segundo tipo de intervenção simultânea, mais vinculado à política tecnológica, diz respeito à criação de condições para o aumento do número de empresas inovadoras, para tornar o esforço de inovação uma estratégia permanente das empresas.

Por fim, no intuito de futuras contribuições à literatura na área de inovação, poder-se-ia examinar os efeitos das fronteiras dos Estados vizinhos a São Paulo. Além disso, um estudo mais aprofundado utilizando a metodologia de dados em painel sobre todas as microrregiões brasileiras permitiria uma investigação mais detalhada do sistema regional brasileiro, apontando suas potencialidades e fragilidades. 


\section{Referências}

Acosta, M., Coronado, D. (2003) Science-technology flows in Spanish regions: an analysis of scientific citations in patents. Research Policy 32, 1783-1803.

Acs, Z. J., Audretsch, D. B. (1989) Patents as a measure of innovative activity. Kyklos-International Review for Social Sciences 42, 171-180.

Albuquerque, E. M., Baessa, A., and Silva, L. (2005) A atividade de patenteamento no Brasil e no Exterior, in FAPESP. (Ed.) Indicadores de Ciência, Tecnologia e Inovação em São Paulo - 2004, 6.1-6.37. FAPESP, São Paulo.

Anselin, L. Local Indicators of Spatial Association - LISA (1995) Geographical Analysis, 27 (2), 93-115.

Anselin, L. (1988) Spatial Econometrics: Methods and Models. Dordrecht: Studies in Operational Regional Science, Kluwer Academic, Boston.

Anselin, L. (2003) Spatial externalities, spatial multipliers and spatial econometrics. International Regional Science Review 26 (3), 153-166.

Anselin, L., Bera, A. K. (1998) Spatial dependence in linear regression models with an introduction to Spatial Econometrics. In: A. Ullah and D. Giles (Eds), Handbook of Applied Economic Statistics, Berlin, 237-289.

Anselin, L., Varga, A., Acs, Z. (1997) Local geographic spillovers between university research and high technology innovations. Journal of Urban Economics 42 (3), 422-448.

Arellano, M., Bond, S. (1991) Some tests of specification for panel data: Monte Carlo evidence and an application to employment equations. Review of Economic Studies, Blackwell Publishing, 58 (2), 277-297.

Arrow, K. (1962) The economic implications of learning by doing. Review of Economic Studies 29, 155-173.

Arthur, B. (1989) Competing technologies, increasing returns and lock in by historical events. The Economic Journal 99 (394), 116-131.

Audretsch, D. B., Feldman, M. P. (1996) R\&D spillovers and the geography of innovation and production. American Economic Review 86 (3), 630- 640.

Badinger, H., Muller, W. G. e Tondl, G. (2004) Regional convergence in the European Union (19851999): a spatial dynamic panel analysis. Regional Studies, 58, p. 241-253.

Baltagi, B. H. (2008) Econometric Analysis of Panel Data. John Wiley \& Sons, West Sussex, Reino Unido.

Baumont, C. (2004) Spatial effects in housing price models: do house prices capitalize urban development policies in the agglomeration of Dijon (1999)? Université de Bourgogne.

Beaudry, C. Schiffauerova, A. (2009) Who's right, Marshall or Jacobs? The localization versus urbanization debate. Research Policy 38, 318-337.

Bilbao-Osorio, B., Rodríguez-Pose, A. (2004) From R\&D to innovation and economic growth in the EU. University of Kentucky. Growth and Change 35 (04), 434-455.

Bosch, M. Lederman, D. Maloney, F. W. (2005) Patenting and research and development: a global view. World Bank Policy Research Working Paper, No. 3739.

Blundell, R., Bond, S. (1998) Initial conditions and moment restrictions in dynamic panel data models. Journal of Econometrics 87 (1), 115-143.

Bode, E. (2004) The spatial pattern of localized R\&D spillovers: an empirical investigation for Germany. Journal of Economic Geography 4 (1), 43-64.

Breschi, S. (1998) Spatial patterns of innovation: evidence from patent data. In: Gambardela, A., Malerba, F. (Eds.), The Organization of Innovative Activity in Europe. Cambridge University Press.

Cabrer-Borrás, B., Serrano-Domingo, G. (2007) Innovation and R\&D spillover effects in Spanish regions: A spatial approach. Research Policy 36 (9), 1357-1371. 
Cameron, A. C., Trivedi, P. K. (2005) Microeconomics: Methods and Applications. Cambridge University Press, Cambridge.

Cano, W. (1977) Raízes da Concentração Industrial em São Paulo. Hucitec, São Paulo.

Carlino, G. A., Chatterjee, S., Hunt, R. M. (2007) Urban density and the rate of invention. Journal of Urban Economics 61 (3), 389-419.

Co, C. (2002) Evidence of the geography of innovation: evidence from patent data. Growth and Change $33(4), 393-423$.

Das, S., Finne, H. (2008) Innovation and co-location. Spatial Economic Analysis 3 (2), 159-189.

De Negri, J. A., Salermo, M. S., Castro, A. B. (2005) Inovações, padrões tecnológicos e desempenho das firmas industriais brasileiras. In: De Negri, J. A., Salermo, M. S. (Eds.), Inovações, Padrões Tecnológicos e Desempenho das Firmas Industriais Brasileiras. Brasília: IPEA 5-46.

Diniz, C. (1994) Polygonized development in Brazil: neither decentralization nor continued polarization. International Journal of Urban and Regional Research 18, 293-314.

Diniz, C. C., Gonçalves, E. (2005) Economia do conhecimento e desenvolvimento regional no Brasil. In: I Encontro de Estudos Regionais e Urbanos. São Paulo.

Ejermo, O. (2005) Technological diversity and Jacobs' externality hypothesis revisited. Growth and Change 36 (2), 167-195.

Feldman, M. P., Audretsch, D. B. (1999) Innovation in cities: science-based diversity, specialization and localized competition. European Economic Review 43 (2), 409-429.

Feldman, M. P., Florida, R. (1994) The geographic sources of innovation: Technological Infrastructure and Product Innovation in the United States. Annals of the Association of American Geographers 84 (2), 210-229.

Fritsch, M; Franke, G. (2004) Innovation, regional spillovers and R\&D cooperation. Research Policy 33, 245-255.

Getis, A., Griffith, D. A. (2002) Comparative spatial filtering in regression analysis. Geographical Analysis 34, 130-140.

Getis, A., Ord, J.K. (1992) The analysis of spatial association by use of distance statistics. Geographical Analysis 24, 189-206.

Glaeser, E.L., Kallal, H. D., Scheinkman, J. A., Shleifer, A. (1992) Growth in cities. Journal of Political Economy 100 (6), 1126-1152.

Gonçalves, E. (2007a) O Padrão espacial da atividade inovadora brasileira: uma análise exploratória. Estudos Econômicos 37 (2), 403-433.

Gonçalves, E. (2007b) Firma e território: três ensaios sobre inovação em ambientes periféricos. Belo Horizonte: CEDEPLAR/UFMG (Tese).

Gonçalves, E. Almeida, E. S. (2009) Innovation and spatial knowledge spillovers: evidence from Brazilian patent data. Regional Studies, 43 (4), 513-528.

Greunz, L. (2002)The innovation process of European regions. Brussels Economic Review 45 (4), 59-94.

Greunz, L. (2004) Industrial structure and innovation: evidence from European regions. Journal of Evolutionary Economics 14 (5), 563-592.

Griliches, Z. (1979) Issues in assessing the contribution of research and development to productivity growth. Bell Journal of Economics 10 (1), 92-116.

Griliches, Z. (1990) Patent statistics as economic indicators: a survey. Journal of Economic Literature 28 (4), 1661-1707.

Iara, A. Traistaru, I. (2004) How flexible are wages in EU accession countries? Labour Economics 11 (4), 431-450.

INEP. Dados sobre educação. 2008. Disponível em: < http://www.edudatabrasil.inep.gov.br/>. Acesso em 30 jan 2008. 
INPI. Dados sobre patentes - 2006. Disponível em: <http://www.inpi.gov.br/menu-esquerdo/patente/ pasta_estatisticas/instituto/estatisticas.

Jacobs, J. (1969) The Economy of Cities. Nova York: Random House.

Jaffe, A. B. (1989) Real effects of academic research. The American Economic Review 79 (5), 957-970.

Jaffe, A.B., Henderson, R. M., Trajtenberg, M. (1993) Geographic localization of knowledge spillovers as evidenced by patent citation. Quarterly Journal of Economics 63 (3), 577-598.

Johnston, J., Dinardo, J. (1997) Econometric Methods. McGraw-Hill Book Company, 4. ed, New York.

Koo, J. (2005) Agglomeration and spillovers in a simultaneous framework. The Annals of Regional Science 39 (1), 35-47.

Koo, J. (2007) Determinants of localized technology spillovers: role of regional and industrial attributes. Regional Studies 41 (7), 995-1011.

Lemos, M. B., Moro, S., Domingues, E. P., Ruiz, R. M. A. (2005) Organização territorial da indústria no Brasil. In: Negri, J.A. e Salermo, M. (Eds.). Inovação, Padrões Tecnológicos e Desempenho das Firmas Industriais Brasileiras. Brasília: IPEA 325-364.

Marshall, A. (1982) Princípios de Economia. São Paulo: Abril Cultural.

Moreno, R., Paci, R., Usai, S. (2004) Spatial spillovers and innovation activity in European regions. European Regional Science Association 3 (10), 1793-1812.

Moreno, R., Paci, R., Usai, S. (2005) Geographical and sectoral clusters of innovation in Europe. Original Paper 39 (4), 715-739.

Ord, J. K., Getis, A. (1995) Local spatial autocorrelation statistics: distributional issues and an application. Geographical Analysis 27 (4), 286-306.

Paci, R., Usai, S. (2000) The role of specialization and diversity externalities in the agglomeration of innovative activities. Rivista Italiana degli Economisti 2 (2), 237-268.

Panne, G. V. D. (2004) Agglomeration externalities: Marshall versus Jacobs. Journal of Evolutionary Economics 14 (5), 593-604.

Pavitt, K. (1984) Sectoral patterns of technical change: towards a taxonomy and a theory. Research Policy 13 (6), 343-373.

PIA. (2006) Pesquisa Industrial Anual - inovação tecnológica. Rio de Janeiro, IBGE.

PINTEC. (2005) Pesquisa de Inovação Tecnológica Industrial- Rio de Janeiro, IBGE.

Quadros, R., Brisolla, S., Furtado, A., Bernardes, R. (2001) Força e Fragilidade do Sistema de Inovação Paulista. São Paulo em Perspectiva 14 (3), 124-141.

RAIS. (2006) Relatório Anual de Informações Sociais. Brasília, Ministério do Trabalho.

Romer, P. (1986) Increasing returns and long-run growth. Journal of Political Economy 94 (5), 1002-1037.

Romer, P. (1990) Endogenous technological change. Journal of Political Economy 98 (2), 71-102.

Simmie, J. (2001) Innovation and agglomeration theory. In: Simmie, J. (Ed.), Innovative Cities. New York: Spon Press, 11-52.

Souza, M. C., Garcia, R. (1999) Sistemas Locais de Inovação em São Paulo. In: Cassiolato, J. E., Lastres, H. M. M. Globalização e Inovação Localizada: Experiências de Sistemas Locais no Mercosul. Brasília: IBICT/MCT, 300-334.

Wood, P. (2001) Conclusions: innovative cities in Europe. In Simmie, J (Ed.), Innovative Cities. New York: Spon Press 231-247. 


\section{ANEXO}

ANEXO 1 - Estatísticas Descritivas de todas as Variáveis Utilizadas

\begin{tabular}{ccccc}
\hline Variáveis & Média & Desvio-Padrão & Mínimo & Máximo \\
\hline $\mathrm{I}_{\mathrm{t}}$ & 0,00005 & 0,00071 & 0,00000 & 0,00056 \\
$\mathrm{I}_{\mathrm{t}-1}$ & 0,00005 & 0,00007 & 0,00000 & 0,00056 \\
$\mathrm{PD}_{\mathrm{t}-1}$ & 0,00631 & 0,00376 & 0,02100 & 0,02350 \\
$\mathrm{D}_{\mathrm{t}}$ & 0,27833 & 0,20995 & 0,00294 & 1,00000 \\
$\mathrm{~S}_{\mathrm{t}}$ & 0,47586 & 0,05730 & 0,16112 & 0,61170 \\
$\mathrm{E}_{\mathrm{t}}$ & 0,01613 & 0,01218 & 0,00000 & 0,05359 \\
\hline
\end{tabular}

Fonte: Elaboração própria.

ANEXO 2 - Matriz de Correlação de Pearson

\begin{tabular}{|c|c|c|c|c|c|}
\hline Variáveis & $\mathrm{I}_{\mathrm{t}-1}$ & $P D_{t-1}$ & $D_{t}$ & $\mathrm{~S}_{\mathrm{t}}$ & $\mathrm{E}_{\mathrm{t}}$ \\
\hline $\mathrm{I}_{\mathrm{t}-1}$ & 1 & & & & \\
\hline \multirow[t]{2}{*}{$P D_{t-1}$} & 0,28311 & 1 & & & \\
\hline & $(<0,0001)$ & & & & \\
\hline \multirow[t]{2}{*}{$D_{t}$} & $-0,20531$ & $-0,35243$ & 1 & & \\
\hline & $(<0,0001)$ & $(<0,0001)$ & & & \\
\hline \multirow[t]{2}{*}{$\mathrm{S}_{\mathrm{t}}$} & 0,03743 & $-0,32876$ & 0,31928 & 1 & \\
\hline & $(0,4330)$ & $(<0,0001)$ & $(<0,0001)$ & & \\
\hline \multirow[t]{2}{*}{$E_{t}$} & 0,43844 & 0,19618 & $-0,15888$ & 0,25573 & 1 \\
\hline & $(<0,0001)$ & $(<0,0001)$ & $(<0,0001)$ & $(<0,0001)$ & \\
\hline
\end{tabular}

Fonte: Elaboração própria.

Nota: Encontra-se em parênteses o valor da probabilidade ( $p$-value). 